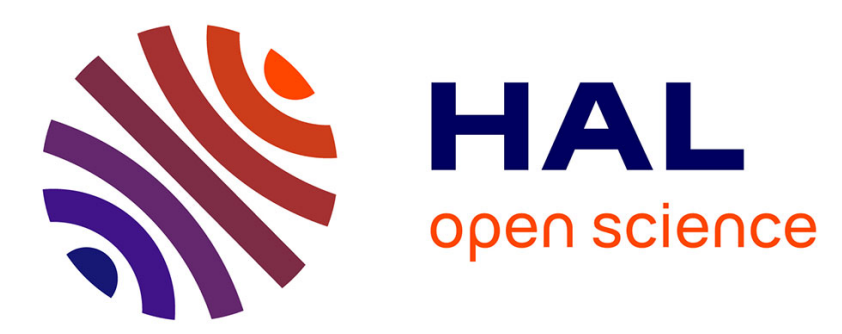

\title{
A modified dissipated energy fatigue criterion to consider the thermo-oxidative ageing of electrically conductive silicone adhesive joints
}

Alexandre Jouan, Andrei Constantinescu

\section{- To cite this version:}

Alexandre Jouan, Andrei Constantinescu. A modified dissipated energy fatigue criterion to consider the thermo-oxidative ageing of electrically conductive silicone adhesive joints. International Journal of Fatigue, 2018, 116, pp.68-79. 10.1016/j.ijfatigue.2018.06.005 hal-01819056

\section{HAL Id: hal-01819056 \\ https://hal.science/hal-01819056}

Submitted on 27 May 2020

HAL is a multi-disciplinary open access archive for the deposit and dissemination of scientific research documents, whether they are published or not. The documents may come from teaching and research institutions in France or abroad, or from public or private research centers.
L'archive ouverte pluridisciplinaire HAL, est destinée au dépôt et à la diffusion de documents scientifiques de niveau recherche, publiés ou non, émanant des établissements d'enseignement et de recherche français ou étrangers, des laboratoires publics ou privés.

\section{(c)(1)}

Distributed under a Creative Commons Attribution| 4.0 International License 
Title: A modified dissipated energy fatigue criterion to consider the thermo-oxidative ageing of electrically conductive silicone adhesive joints

Authors: Alexandre Jouan ${ }^{a}$ (corresponding author), Andrei Constantinescu ${ }^{a}$

a Laboratoire de Mécanique des Solides, CNRS, Ecole Polytechnique, Université Paris-Saclay, 91120 Palaiseau, France, alexandre.jouan@polytechnique.edu, andrei.constantinescu@polytechnique.edu

Key words: adhesive joint fatigue, silicone adhesive, thermo-oxidative ageing, stress-life approach

Abstract: The increasing use of adhesive joints as an assembly technique in various technical fields at the expense of the classical soldering and welding technique brings up the critical questions of their reliability and their lifetime prediction. Fatigue testing of adhesive joints has therefore gained importance in the last few decades, in order to validate the choice of adhesives in structural applications. The influence of environment and ageing on the fatigue life has also gained attention as adhesives are used in wet, or oxidative, or high temperature atmospheres. This paper presents an experimental fatigue study led on a commercial conductive silicone adhesive following the classical stress-life approach. The bonded assemblies were fatigue tested either at virgin state or after thermo-oxidative ageing. Based on results of the fatigue tests, a law relying on two mechanical predictors including the dissipated energy is proposed that considers the influence of a thermo-oxidative ageing of the adhesive joint.

\section{Introduction}

In the last decades, adhesive joints (also denoted as "adhesive layers") gained great interest as a sustainable assembly solution for various industries, such as aeronautics and automotive (1), seawater (2), offshore (3) and electronics (4). In the specific framework of electronics, the replacement of soldering by adhesive bonding presents several benefits: (i) an easier assembly process, (ii) lower temperatures during the manufacturing process, (iii) an alternative to lead soldering, and (iv) the possibility to bind diverse materials (not only metals) together, among other advantages. The progressive expansion of adhesive joints for technical and structural purposes yields the study of their reliability with respect to fatigue loadings and ageing highly necessary.

Adhesive joints for electronics usually consist of a polymeric matrix filled with metallic particles, which permit to reach convenient electrical and thermal properties needed for their final applications. From a mechanical point the exhibit an increased stiffness when compared with sole polymer, however their plastic, viscous, fatigue or aging properties will depend on different parameters like the polymer type, particle shape and filler content as well as the environment.

The mechanical definition of fatigue is the progressive damage accumulation of a material under cycling loading, leading to final macroscopic failure after a certain number of loading cycles. As for metallic materials, it is widely considered that fatigue failure of an elastomer implies two distinct phases (5): 
- An initiation phase, characterized by the nucleation of defects (microcracks, cavities) in originally defect-free material areas leading to the initiation of a macroscopic crack.

- A propagation phase, characterized by the propagation of the macroscopic crack formed during the initiation phase. The macroscopic crack propagation is defined by an observable force drop under an imposed displacement loading, or inversely a displacement increase under an applied force loading. By comparison, a microscopic crack will not be observable neither in displacements nor in forces at the macroscopic scale.

Fatigue models can be devised in three clusters (6) with respect to their precise prediction objective and underlying modelling assumptions: first, the crack initiation approach focuses on the quantitative description of the initiation phase. This approach is mainly described by damage models, either by an empirical damage accumulation (see for example (7), (8) or (9)) or derived from a theory of continuum damage mechanics (see (10), (11), (12) or (13)). Second, the crack propagation approach describes the second phase of the fatigue failure once a macroscopic crack has nucleated from the initiation phase. This approach is mainly based on the framework of the fracture mechanics and the energy release rate $G$. Equation like the Paris power law used in (14) can be used to link the energy release rate $G$ to the crack growth $\mathrm{d} a / \mathrm{d} N$. The Paris' law can be modified (15) to fit the experimental data. Cohesive zone models have also been used to describe the propagation phase (16) (17) (18). Last, the stress-life approach links the stress amplitude (or the amplitude of any other relevant mechanical parameters) to the number of cycles to failure to get the so-called S-N curve or Wöhler curve (19) (20) (21) (22) (23). As a consequence, this approach usually includes both initiation and propagation phases, depending of the definition of the failure. As a matter of fact, the definition of the failure of a given specimen is not unique but requires choices from the experimentalist.

For silicone adhesive bonding in the absence of fillers, (24) discusses the failure of the joints based on a finite element computation to assess the stress and strain state and concludes that true strain magnitude is the pertinent fatigue life predictor. Complex damage evolution models have been proposed for reinforced rubber in (25), in the case where particles are close to a sphere and the filler ratio stay small, i.e. the distance between fillers is several times larger than the particle diameter. Other recent papers study the influence of different parameters on the fatigue life. For example (26) probes the effect of surface roughness and adhesive thickness on the fatigue resistance of an aluminium one-component polyurethane adhesive joint for the automotive industry and proposes an optimal combination of the two factors, without analyzing the physical mechanism of failure.

Durability performances of adhesive joints with respect to thermal and thermo-oxidative ageing has been quite extensively investigated in the literature. We can cite in particular (27) that models the influence of a high temperature ageing at a given humidity ratio on the peel strength of adhesive films with an exponential decay. Su et al. (28) showed that thermal ageing can sometimes improve the durability properties of the adhesive joints when moisture is not present, whereas environmental or high humidity ageing almost systematically provokes a dramatic decrease of the joint reliability with the exposure time. The recent study (29) performed fatigue tests at different temperatures on bulk rubber 
samples that underwent thermo-oxidative ageing of diverse temperature and exposure time to identify empirical laws that gives the shift of the Wöhler curve as a function of the test temperature and the ageing parameters. The reader can also refer to the review (6) for other references on the influence of thermal ageing on the fatigue properties of the adhesive joints.

The aim of this paper is to analyze a series of fatigue experiments on a commercial conductive silicone adhesive and propose a reliable prediction criterion that takes into account the thermo-oxidative ageing of the bonded assembly. The particular material configuration with a high filler ratio and complex filler shape excludes a fine modeling of the damage evolution as proposed in (25).

The fatigue study proposed here was therefore performed in the framework of the stress-life approach on either new or previously thermo-oxidatively aged silicone adhesive joints until complete failure of bonded assemblies. The paper will present the material and the fatigue results based on an overview of failure criteria. However, the analysis is founded on previous results presenting the complete strain and stress distribution in the joints within different testing configuration published in (30).

The paper is organized as follows: section 2 presents the material and the experimental setup used for testing. Section 3 is a brief review of the basic assumptions of the fatigue criteria under scrutiny. The results of the fatigue tests are discussed in section 4 and are followed by the proposed fatigue law in the section 5 .

\section{Material and experimental setup}

\subsection{Material}

The material studied is a commercial silicone-based Electrically Conductive Adhesive (ECA). The adhesive is a composite material containing silver flakes, for more than $50 \%$ of its volume, in a silicone matrix. The silver flakes insure the electrical and thermal properties needed in standard electronic applications, such as connecting an electronic component on a printed circuit board (PCB). Figure 1 shows a detailed micrograph of the silicone conductive adhesive. One can remark by comparing Figure 1 (a) and (b) that (i) the shape of the silver particles are flat flakes with a typical length about 10 to $15 \mu \mathrm{m}$ and a typical thickness about $1 \mu \mathrm{m}$, and that (ii) the position of the flakes is structured along privileged directions. Both phenomena induce an anisotropic material behavior both in terms of elasticity and failure. However for the sake of simplicity and by lack of statistical information, the induced anisotropy will not be considered next. 


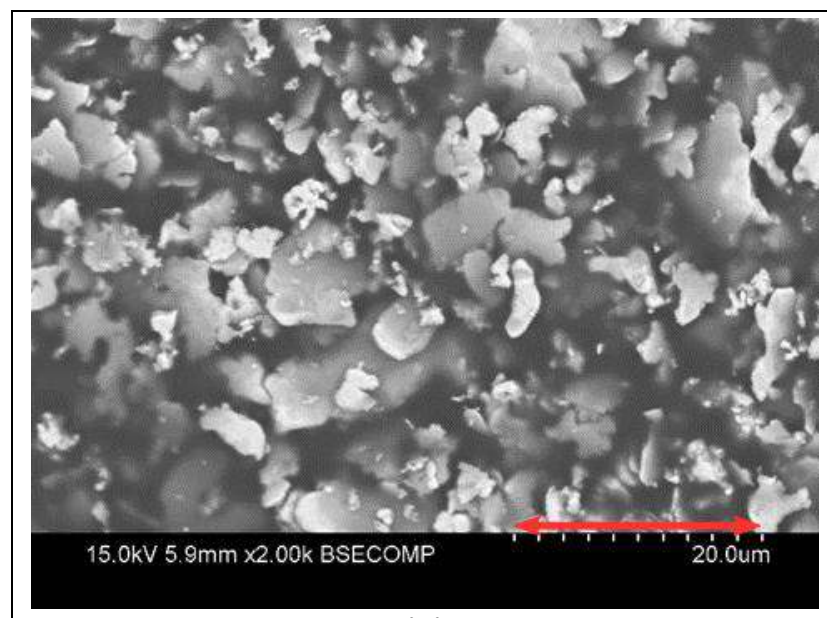

(a)

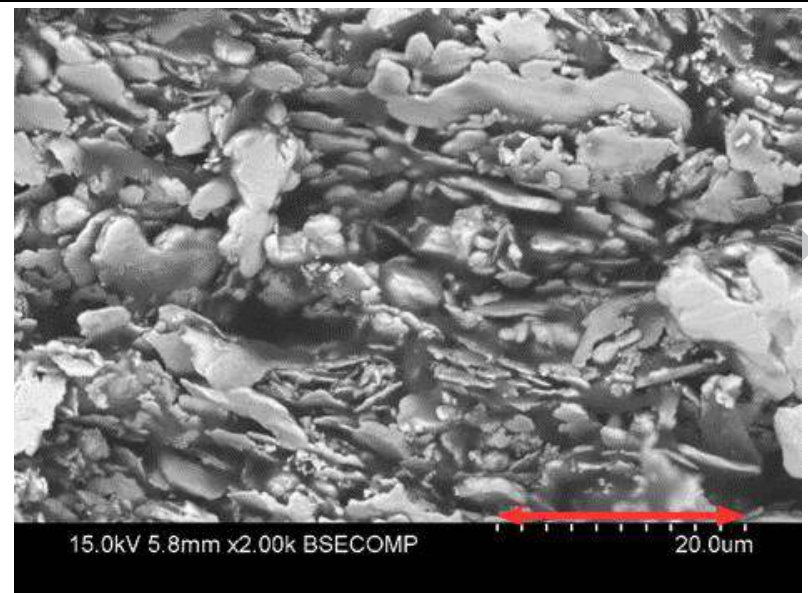

(b)

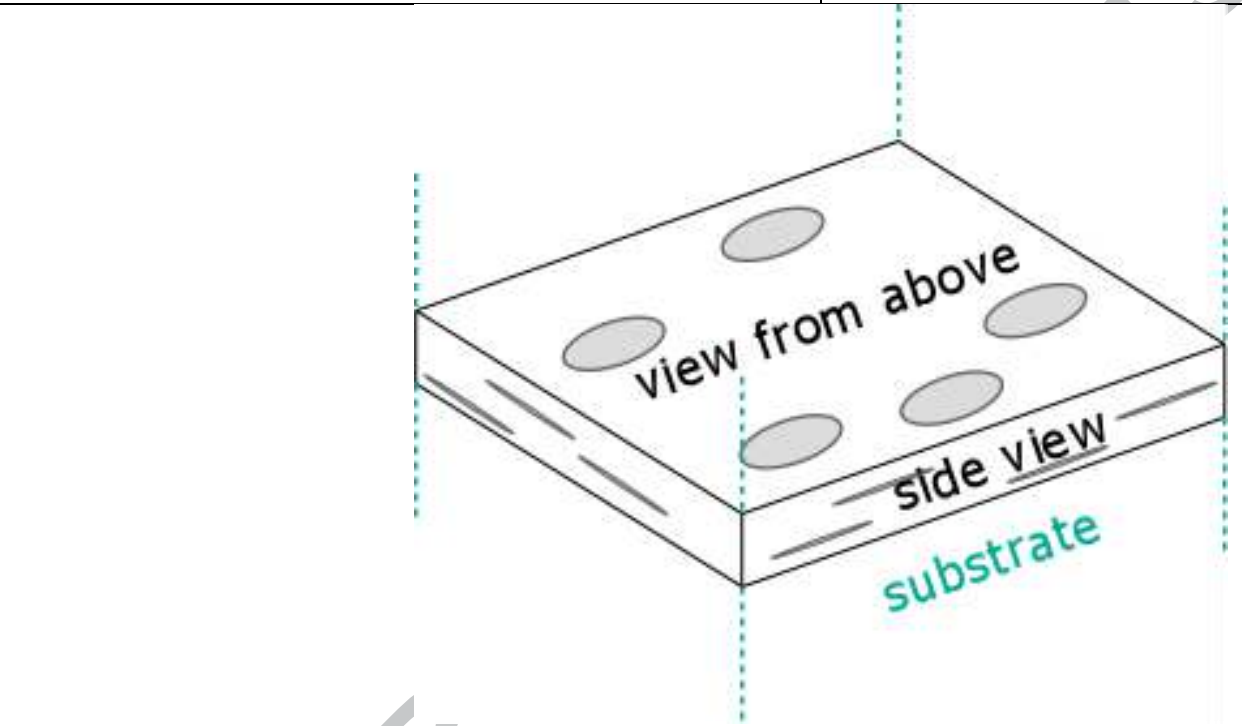

(c)

Figure 1: SEM view from above (a) and side view (b) of the bulk silicone adhesive studied ; the views are defined on the sketch (c). The red scale bars on (a) and (b) correspond to $20 \mu \mathrm{m}$. The greatest typical dimension of the particles is about 10 to $15 \mu \mathrm{m}$.

For confidentiality reasons, the manufacturer or the curing profile of the adhesive will not be disclosed.

\subsection{Material ageing}

Thermo-oxidative ageing on the fatigue behavior of ECA silicone joints was realized in a ventilated oven at $220^{\circ} \mathrm{C}$ for four months. The ventilation of the oven ensures: (i) a constant and regular oxygen proportion in the surrounding atmosphere, and (ii) the exhaustion of the potential adhesive outgassing which will thus not interact with the adhesive joint itself.

The thermo-oxidative ageing can be modeled like chemical aging using the equivalence of the temperature and exposure time with a simple Arrhenius dependence (31): two aged states defined by an 
ageing temperature $T_{i}$ and a time exposure $\Delta t_{i}$ are similar from the point of view of the chemical reaction if

$$
\frac{\Delta t_{1}}{\Delta t_{2}}=\exp \left(-\frac{E_{a}}{k_{B}}\left(\frac{1}{T_{2}}-\frac{1}{T_{1}}\right)\right)
$$

where $E_{a}$ denotes the activation energy of the chemical reaction in $\mathrm{eV}$ units and $k_{B}=8.627$.

$10^{-5} \mathrm{eV} / \mathrm{K}$ denotes the Boltzmann constant. A method to determine the activation energy with ThermoGravimetric Analysis (TGA) is presented in Appendix A.

The relative humidity (also called the $\mathrm{RH}$ ratio) inside the oven will be considered close to $0 \%$ considering the oven temperature.

\subsection{Shear test setup}

The fatigue tests have been performed using a standard tensile machine combined with an on-purpose designed setup, see Figure 2 .

The experimental setup takes advantages of the well-known Thick Adherent Shear Test (TAST) and ARCAN methods. A complete analytical and numerical analysis of the strain and stress fields imposed by the setup is presented in (30). Here, we only describe its key features:

- The adhesive joint section is a $5 \times 5 \mathrm{~mm}$ square, representative of the size of electronic applications. A specific tooling illustrated in Figure 2 (c) that takes advantage of thin metallic foils as shims was designed to assure the alignment of the substrates and to adjust the thickness $h$ of the adhesive layer illustrated on Figure 2 (a) and Figure 3. The latter was measured by optical microscopy after curing, which confirmed an average value of $250 \mu \mathrm{m}$.

- The adhesive joint is bonded on simple substrates, i.e. parallelepiped blocks $5 \times 5 \times 10 \mathrm{~mm}$ with machined grooves at the vicinity of the free edges of the joint to lower any potential stress singularity at these edges (32), see Figure 2 (a). They are machined in A2618 aluminum taking advantage of its relatively low stiffness at room temperature compared to others common metals, which reduces the material discontinuity at the joint-substrate interface level. The bonding surfaces of the substrates were polished to reach an arithmetic roughness $R a$ between 0.5 and $1 \mu \mathrm{m}$, and plated with a 7 to $10 \mu \mathrm{m}$-thick electroless nickel-phosphorus layer and a $0.1 \mu \mathrm{m}$-thick electrolytic gold layer. These treatments reproduce the classical terminations plating used on printed circuit boards (PCB's).

- The L-shaped parts of the setup, see Figure 2 (b), are machined in steel to minimize the bending of the setup and thus prevent normal stresses that are responsible for substantial triaxiality ratio values in the adhesive layer. The extremity of these steel parts was designed to be adapted to the bits of the BOSE 3330 series II tensile test machine used in this study. 


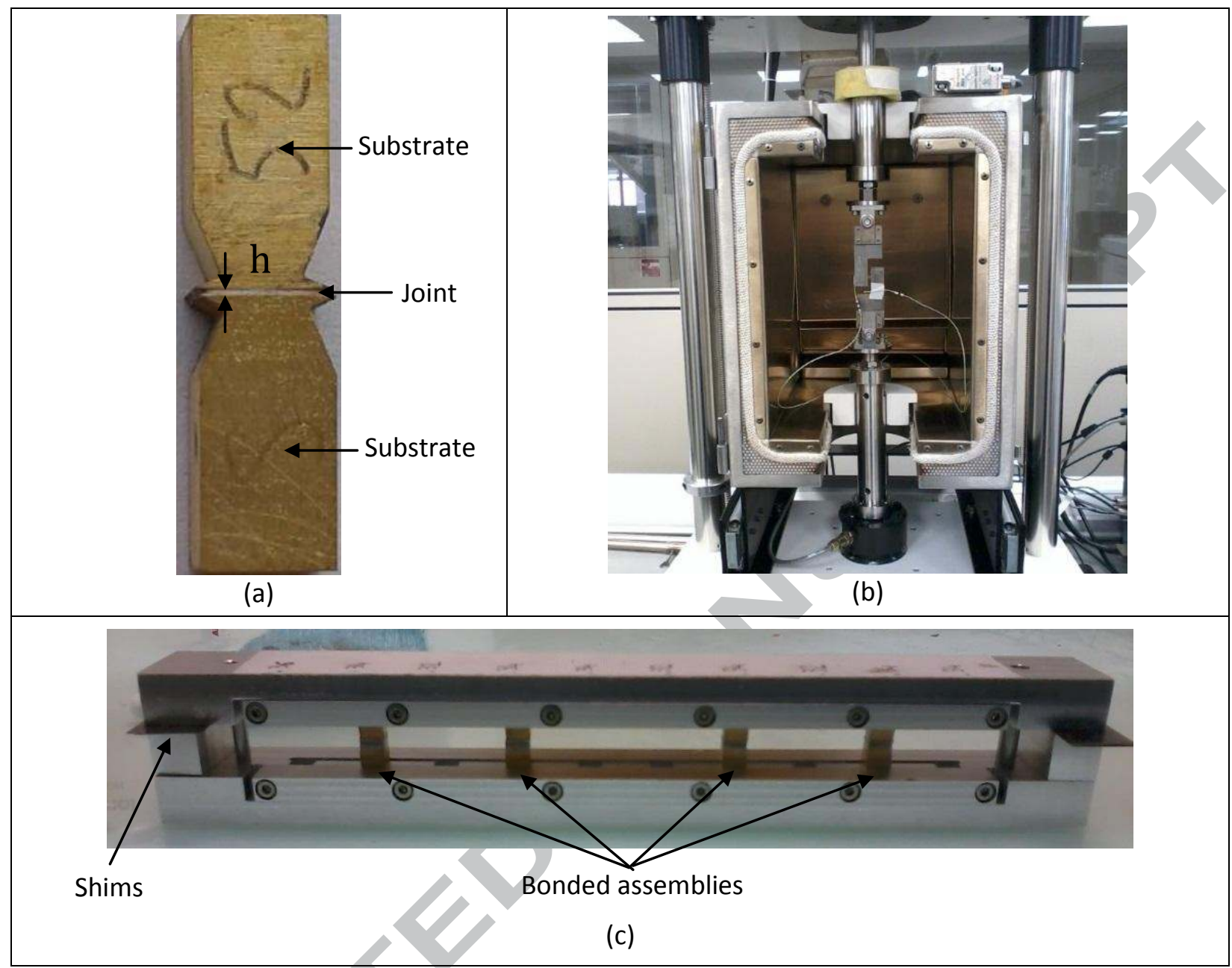

Figure 2: bonded sample (a); test setup mounted in the BOSE tensile machine (b)

As an illustration of the behavior of the setup, Figure 3 represents the deformed state of the setup with a zoom on the joint. The boundary conditions are applied at the extremity of both substrates and illustrated with red symbols on the figure: $\underline{u}=\underline{0}$ for the left substrate and $\underline{u}=d \underline{e_{1}}$ on the right one. The color plot on this figure illustrates the shear strain $\gamma_{12}$ normalized by the imposed shear strain $\gamma_{0}=d / h$ where $h$ denotes the joint thickness. An ideal shear test with rigid adherent without any stress singularity would exhibit $\gamma_{12}=\gamma_{0}$ anywhere within the joint and $\gamma_{12}=0$ in all the other parts of the setup. 


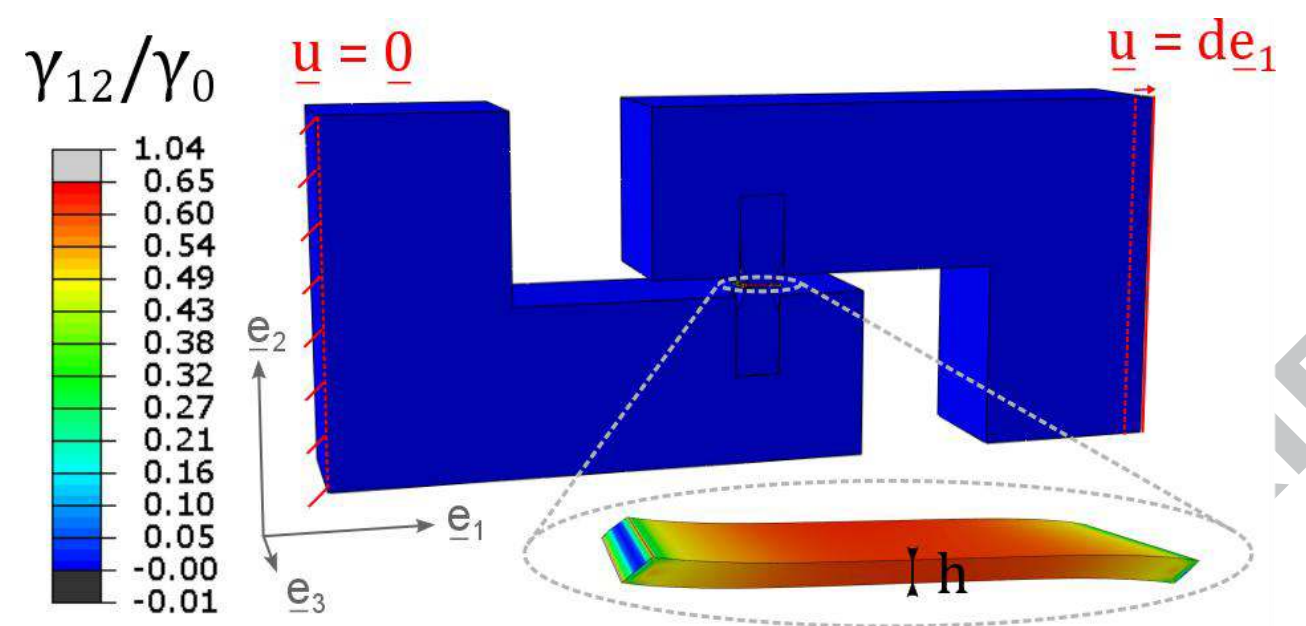

Figure 3: Deformed state of the setup for an imposed loading $\gamma_{0}=d / h=2$ with a zoom on the joint area of thickness $h$. The color plot corresponds to the normalized local shear strain $\gamma_{12} / \gamma_{0}$.

These results were computed using the finite element software ABAQUS ${ }^{\circledR}$. A detailed discussion of mechanical fields and variables (as for example shear stress, strain and strain energy at joint center where their values are maximum, joint shear modulus, etc.) derived from the data of both macroscopic load $F$ and displacement $d$ is presented in (30). These computations will be used to obtain the local fields necessary for the fatigue study from the experimental data $F$ and $d$ measured by the machine cells.

\subsection{Fatigue testing of the bonded samples}

The experimental parameters of the fatigue tests performed with the BOSE tensile machine were set as follows:

Temperature: the tests were performed at room temperature (between $20^{\circ} \mathrm{C}$ and $25^{\circ} \mathrm{C}$ ).

Humidity: the relative humidity $\mathrm{RH}$ ratio could not be controlled in the testing room, but was monitored at about $40 \%$. This range is known to be the most suitable one for electronics.

Loading control: the fatigue tests were performed at constant stress amplitude $\Delta \tau$ under a sinusoidal load. This hypothesis is however only an approximation during the propagation phase when the effective surface of virgin material is decreasing, implying an increase in the stress amplitude at constant load amplitude. Concerning the strain or energy-based mechanical quantities, the value attributed to the test is the value of these quantities at mid-life of the joint. No average load was added to the load signal, meaning that the potential influence of a mean shear stress $\tau_{m}$ is not studied in this paper.

Frequency: the frequency of the sinusoidal load cycles has been set to $10 \mathrm{~Hz}$, in order to perform the tests as quickly as possible without provoking any substantial self-heating of the adhesive joint because of the energy dissipated per cycle due to the viscosity of the material. The self-heating was smaller than $1^{\circ} \mathrm{C}$, as predicted by a numerical model considering the whole test setup and the surrounding 
atmosphere run with the Computational Fluid Dynamics software FloTHERM ${ }^{\circledR}$, and experimentally verified by thermocouple measurements on the free surface of the joint.

\section{Stress-life approach, predictors and fatigue laws}

This paper uses the stress-life approach presented in the introduction section. This approach ultimately defines a lifetime at every material point given the loading history at the considered material point. The failure is expected to happen at the point that presents the shortest lifetime. This approach is appreciated because its formulation usually involves classical mechanical quantities that are often easily accessible by Finite-Elements computations. When performing a fatigue test on a real specimen, the failure can be defined as a macroscopic crack initiation of a given length, a general decrease of the structural stiffness of the specimen, or even the fracture of the whole specimen. Depending the chosen definition of specimen failure, the stress-life approach can cover the only crack initiation phase or also partially or completely include the propagation phase.

The mechanical quantity involved in the computation of the lifetime prediction is called the fatigue predictor, or alternatively the fatigue parameter or damage parameter. A plot of the predictor against the number of cycles to failure is usually referred as a Wöhler curve (also called S-N curve). Given a predictor $\phi$, a fatigue law usually relates the number of cycles to failure $N_{f}$ to the amplitude of the predictor $\phi_{a}=\left(\phi_{\max }-\phi_{\min }\right) / 2$ computed on a load cycle. The most frequent fatigue law is the Basquin law (33):

$$
N_{f}\left(\phi_{a}\right)^{k}=B
$$

or equivalently

$$
N_{f}\left(\frac{\phi_{a}}{\phi_{0}}\right)^{k}=1
$$

with $\phi_{0}^{-k}=B$. If the predictor presents a non-zero average value $\phi_{m}$, then the predictor amplitude can be corrected to get the "effective predictor amplitude" $\phi_{e q}$ that leads to the same number of cycles to failure as the amplitude $\phi_{a}$ superimposed with the mean value $\phi_{m}$. The formulation of the fatigue law simply becomes

$$
N_{f}\left(\frac{\phi_{e q}}{\phi_{0}}\right)^{k}=1
$$

In this case, $\phi_{e q}$ is a function of $\phi_{a}$ and $\phi_{m}$, and $\phi_{e q}\left(\phi_{m}=0\right)=\phi_{a}$. Alternatively, the R-ratio defined as $\phi_{\min } / \phi_{\max }=\left(\phi_{m}-\phi_{a}\right) /\left(\phi_{m}+\phi_{a}\right)$ is also used to describe the mean value $\phi_{m}$. 
The reader can refer to the review (34) for classical fatigue law formulations other than the Basquin power law.

The fatigue predictors investigated in this paper for the study of the fatigue lifetime of new and aged silicone adhesive joints are listed below. Some of them are typical stress-life predictors, whereas the others come from particular studies of specific materials.

- The shear strain amplitude $\Delta \gamma=\left(\gamma_{\max }-\gamma_{\min }\right) / 2$ at the center of the joint. This quantity is computed from the macroscopic load and displacement signals employing a numerical abacus (see paragraph 2.3).

- The shear stress amplitude $\Delta \tau=\left(\tau_{\max }-\tau_{\min }\right) / 2$ at the center of the joint. As for the shear strain $\Delta \gamma$, the shear stress is deduced from the load and displacement signals using a numerical abacus (see paragraph 2.3).

- The range of the volumetric density of elastic energy $\Delta W=W_{\max }-W_{\min }$ at the center of the joint. In the framework of small strains, the elastic energy can be approximated by the quantity

$\gamma$.

- The volumetric density of energy dissipated per cycle at the center of the joint. In the framework of small strains, the dissipated energy can be approximated by the quantity $\sin \delta$, where $\delta$ denotes the phase shift between the load and the displacement signals. This predictor is inspired by the references (35) and (36) on metallic alloys under thermomechanical loadings (where the material has a viscoplastic temperature dependent behavior and when loadings cycles exhibit a hysteretic behavior). As polymers present a dissipated energy even at room temperature due to their viscous nature, it was therefore chosen to investigate this predictor for this study.

- The configurational stress amplitude $\quad W$. This predictor is the smallest eigenvalue of the configurational stress tensor (37). The work of Verron et al. (38) in the framework of natural rubber fatigue makes it a natural candidate for the study of fatigue of rubbery materials.

- The amplitude of an optimized predictor $W$, with a coefficient adjusted with respect to a certain law expressed below. This coefficient was introduced to optimize the configurational stress amplitude which primarily consists in a linear combination of two previous predictors $\Delta \tau$ and $W$. No clear physical significance of $b_{\text {opt }}$ is given in is study.

\section{Results of the fatigue tests}

In this paper, the specimen failure was defined in accordance with the final electronic application of the adhesive joints: (i) the joint stiffness shall remain strictly positive to support the electronic component, and (ii) the joint electrical conductivity shall not vary more than $10 \%$.

The electrical resistance of the setup was preliminary monitored during a simple monotonous shear test up to joint complete failure using a multimeter scanner. It has been noticed that the measured electrical 
resistance did not increase more than $1 \%$ after joint fracture as long as the two fracture surfaces stay in contact. It has therefore been chosen to define the number of cycles to failure as the number of cycle to complete fracture of the joint. Given the dimensions of the joints, this criterion can also be seen as the initiation of a $5 \mathrm{~mm}$-long crack. This choice implies among others that both initiation and propagation phases are completely included in the failure definition.

The cyclic tests were performed until $N_{\max }=10^{7}$ cycles, which lasts about 12 days at $10 \mathrm{~Hz}$. The bonded specimens still intact after $10^{7}$ cycles are designated as survivors. The Table 1 presents the number of bonded samples tested in this study:

\begin{tabular}{|c|c|c|}
\hline Result $\quad$ Ageing state & New & Aged \\
\hline Failure(s) & 12 & 6 \\
\hline Survivor(s) & 0 & 3 \\
\hline
\end{tabular}

Table 1: Number of bonded samples tested in fatigue

The Appendix B lists the results of the fatigue tests including the values of the different predictors considered in this study. The following graphs display the fatigue results of new and aged silicone adhesive joints, expressed as Wöhler diagrams: Figure 4 to Figure 6 illustrate the results in terms of the predictors $\Delta \tau$ and $\Delta \gamma, \Delta W$ and $W_{d}$, and $\Delta \Sigma$ an $\Delta \Sigma_{\text {opt }}$ respectively.

* failures (new) $\quad$ failures (aged) $\diamond \quad$ survivors (aged)

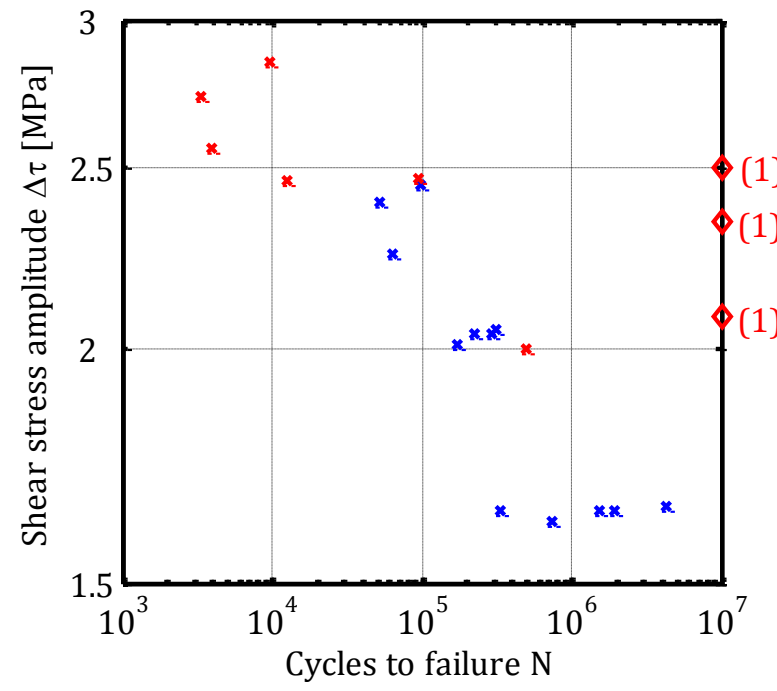

(a)

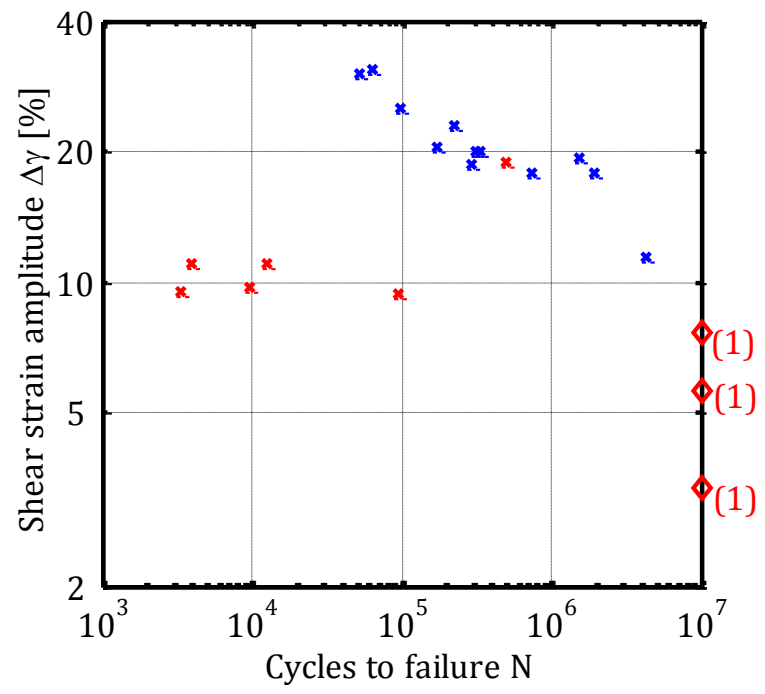

(b)

Figure 4: fatigue results of new and aged silicone joints plotted against $\Delta \tau$ (a) and $\Delta \gamma$ (b)

Figure 4 (a) and (b) display a comparison of the lifetimes in terms stresses and strains respectively. The relative shifts of the clouds of aged and non-aged failure points (red and blue crosses in the graphs) can be read as a stiffening of the joints during ageing. More precisely, aged joints failed at smaller shear strain amplitude $\Delta \gamma$ than non-aged joints but also at larger shear stress amplitudes $\Delta \tau$ than non-aged joints. This is 
in accordance with prior observations (31) which stated that natural rubber gets stiffer during thermooxidative ageing.

* failures (new) * failures (aged) $\diamond \quad$ survivors (aged)

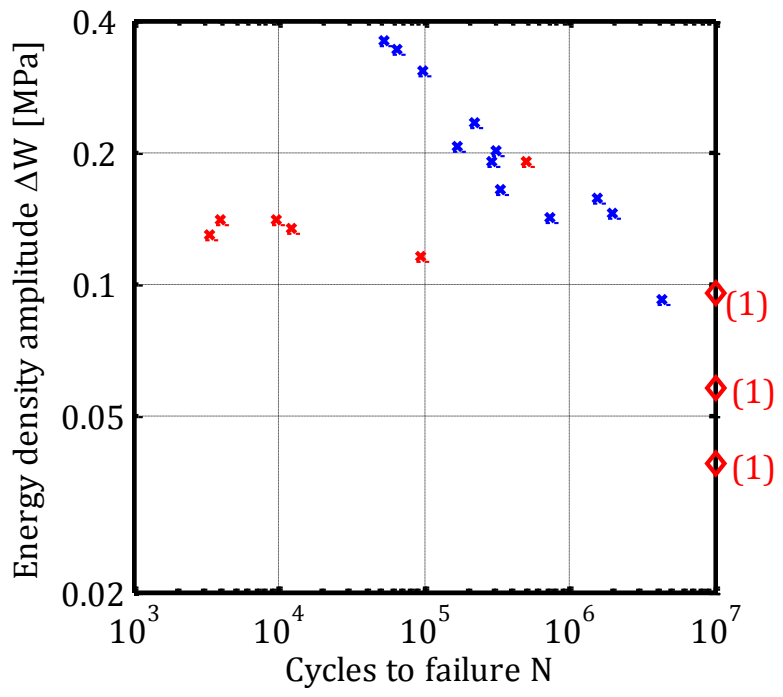

(a)

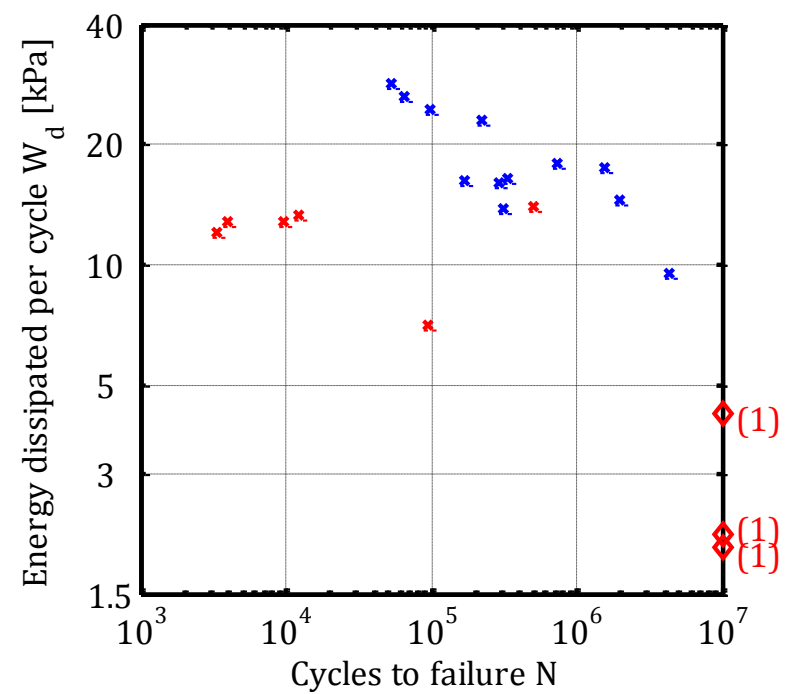

(a)

Figure 5: fatigue results of new and aged silicone joints plotted against $\Delta W$ (a) and $W_{d}$ (b)

* failures (new) * failures (aged) $\diamond$ survivors (aged)

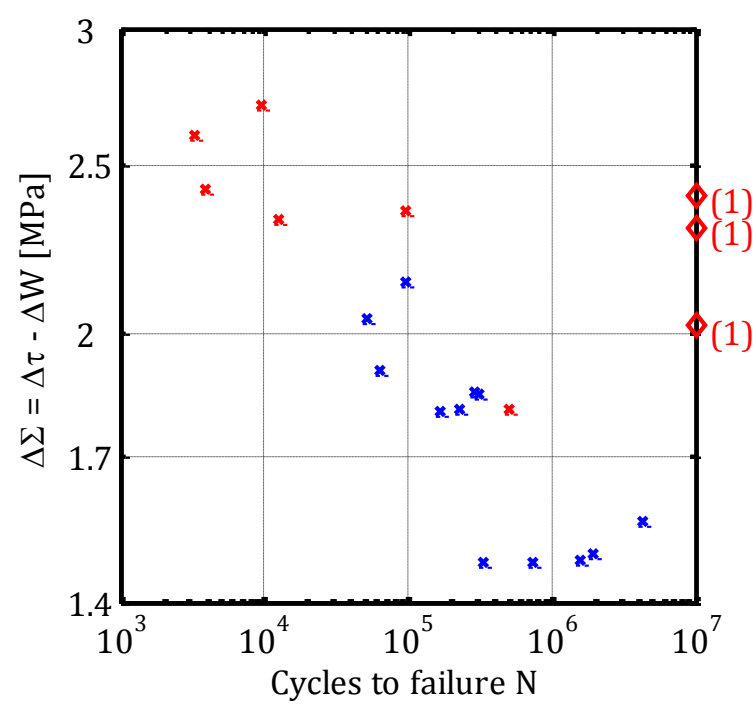

(a)

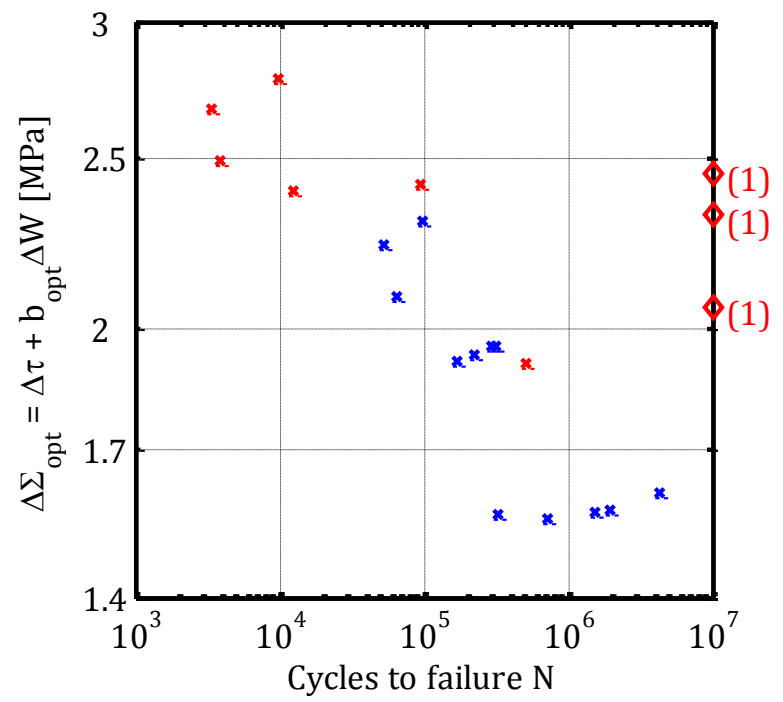

(b)

Figure 6: fatigue results of new and aged silicone joints plotted against $\Delta \Sigma$ (a) and $\Delta \Sigma_{\text {opt }}$ (b) with $b_{\text {opt }}=-0.47$

As mentioned above, the fatigue tests were load-controlled. Therefore, lower dispersion on the results with the stress-based predictors $(\Delta \tau, \Delta \Sigma)$ is expected compared to the dispersion of the strain or energybased predictors $\left(\Delta \gamma, \Delta W, W_{d}\right)$. However, concerning the new joints (blue crosses on Figure 4 to Figure 6 ), the contrary is noticed with a larger dispersion for the strain and energy-based predictors compared 
to the stress-based ones. This observation is, to the authors' knowledge, not explained by a clear material phenomenon so far.

Moreover, the three survivors are characterized by minimal values of the strain and energy-based predictors, whatever the state (new or aged) of the joints. This is not the case for the stress-based predictors, for which the aged survivors were obtained at significantly larger values of the predictors than the failures of new joints. Therefore, a purely stress-based predictor cannot unify the data of failures and survivors for new and aged joints. The stiffening during ageing highlighted above could be a potential explanation for this observation.

However, no particular Wöhler curve can be plotted from only the failures of aged joints when considering the strain and energy-based predictors: the Wöhler curve would indeed be horizontal, or would even have a non-physical positive slope. On the contrary, failures of both new and aged joints seem to lie in the same region when considering the stress-based predictors, allowing to draw a unique Wöhler curve. The graphic alignment of the failures is slightly improved when considering the configurational stress $\Delta \Sigma$ instead of the shear stress $\Delta \tau$. As a consequence, the coefficient $b_{\text {opt }}$ of the optimized predictor $\Delta \Sigma_{o p t}$ will minimize the dispersion (in the least-square sense) of the failures of both new and aged joints with respect to a classical Basquin curve, represented by a straight line in a log-log plot.

Additionally, the reader can find in Appendix $\mathrm{C}$ a discussion about the evolution of the mechanical behavior during the fatigue life for failed joints and survivors. In particular, stages can be defined in the case of failed joints like in (39), whereas the survivors do not exhibit such stages.

\section{Proposal of a fatigue law}

According to the observations of the previous section, a fatigue law combining the two predictors categories and presenting the following key points be will proposed:

- a classical Basquin law formulation on a stress-based predictor unifying the new and aged failures

- a threshold on a strain or energy-based predictor taking into account the survivors obtained at the smallest values of these predictors.

The proposed law finally reads as follows:

$$
N\left(\frac{\sigma_{e q}}{\sigma_{0}}\right)^{k}=1 \text { with } \sigma_{e q}=\left\{\begin{array}{l}
\Delta \tau+b_{o p t} \Delta W \text { if } W_{d}>W_{s} \\
0 \text { if } W_{d} \leq W_{s}
\end{array}\right.
$$


where $\sigma_{0}$ and $k$ denote the Basquin parameters and $W_{s}$ denotes the threshold of dissipated energy. The Figure 7 (a) and (b) displays the law with the following coefficient values identified by a least-square regression: $\sigma_{0}=6.86 \mathrm{MPa}, k=9.65, W_{s}=5.0 \mathrm{kPa}$ and $b_{\text {opt }}=-0.47$.

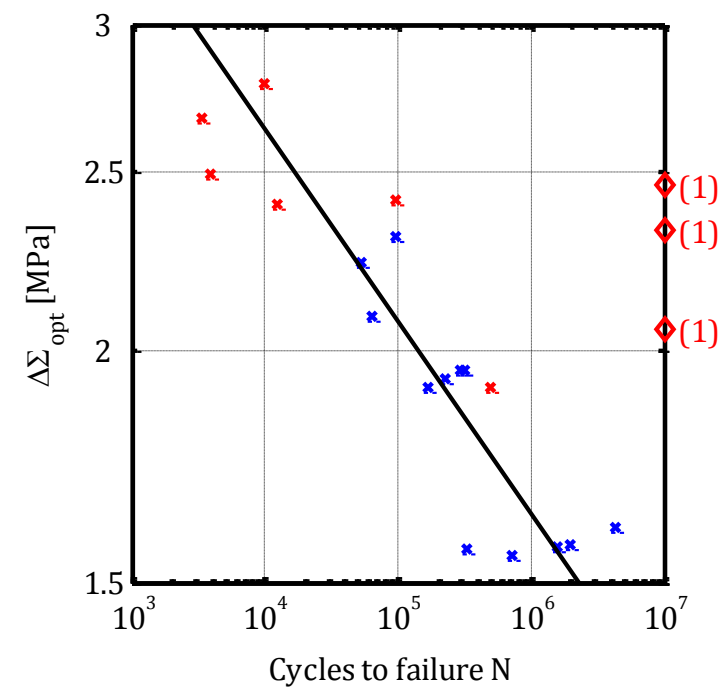

(a)

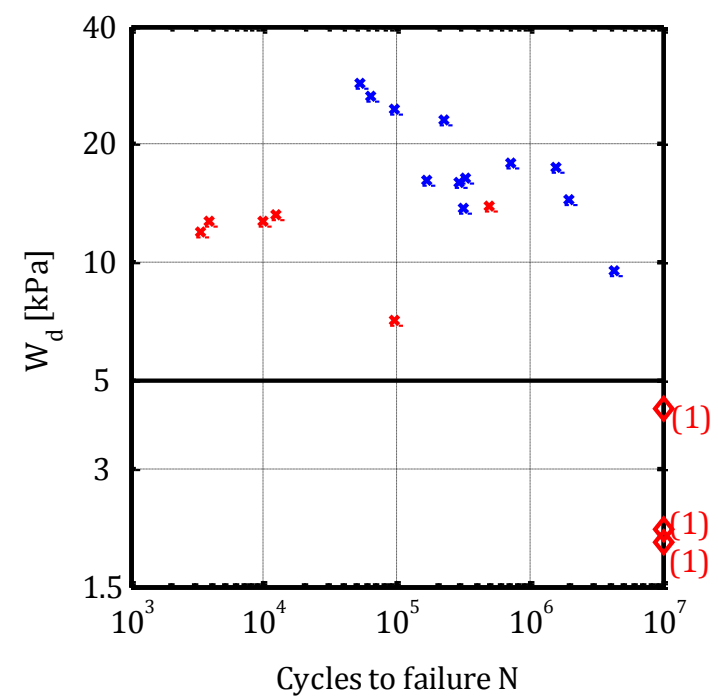

(b)

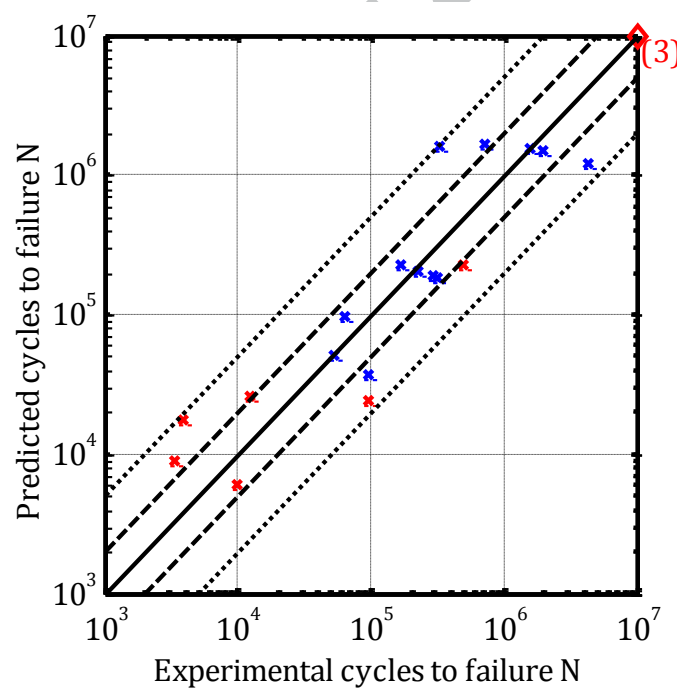

(c)

Figure 7 : fatigue lax unifying the results of new and aged joints combining the predictors $\Delta \Sigma_{\text {opt }}$ (a) and $W_{d}$ (b) ; plot of the predicted lifetime over the experimental lifetime (c), the dotted lines represent a factor 2 and 5 between both lifetimes.

The dispersion of the law predictions plotted against the experimental results is illustrated on Figure 7 (c). The predictions are consistent with the results within a scatter of 5 in terms of lifetime. Several hypotheses can explain this scatter:

- It is probably unrealistic to pretend to get a small dispersion with a simple Basquin formulation when identifying the coefficients on four decades of cycles to failures $N$. Moreover, it is generally admitted that the dispersion increases with $N$, and having $N_{\max }=10^{7}$ is not so common in 
polymer fatigue due to the limitation of the cycle frequency because of the self-heating of the material.

- Both cohesive and adhesive failure mechanisms have been observed with a Scanning Electron Microscope, as illustrated on Figure 8. Having two different failure mechanisms can increase the dispersion because of the varying proportion of each mechanism from one specimen to another. It should be noted here that the two mechanisms have been observed on each specimen, whatever the ageing state (40).

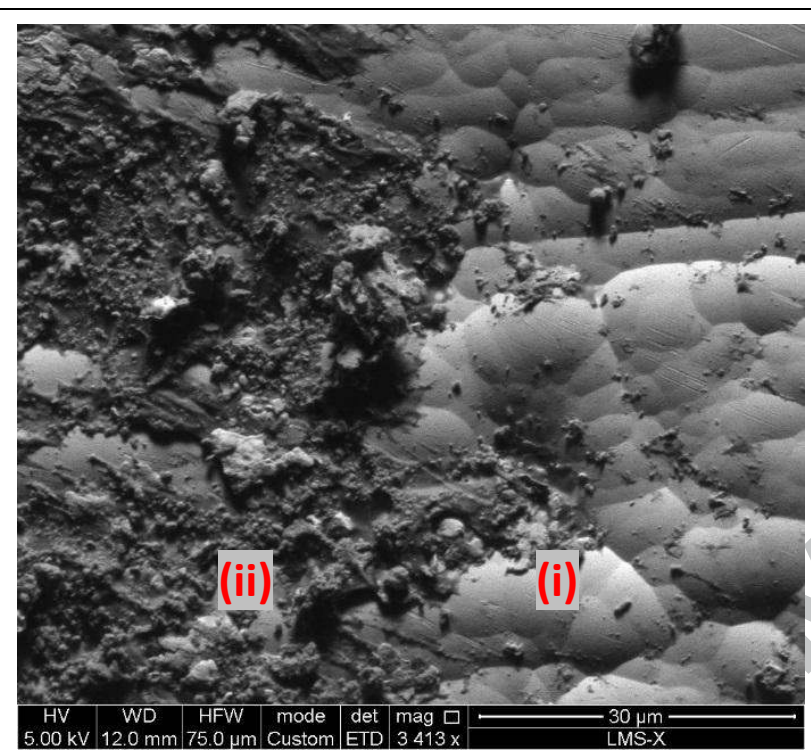

(a)

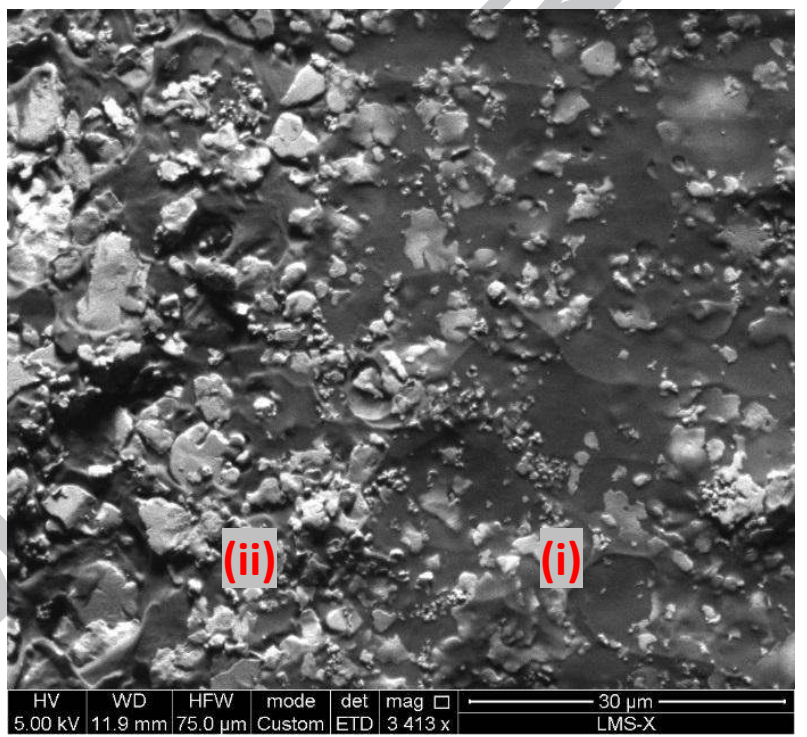

(b)

Figure 8: fracture surfaces of new joints on initially bonded substrates. The zones (i) present a purely adhesive fracture whereas the zones (ii) show a mixed fracture surface with a layer of silicone matrix that remains on the substrate (a) and some matrix-filler debonding (b). Aged joints present simialr fracture surfaces with the two different kinds of zones (i) and (ii).

Nevertheless, the law identification is considered as satisfactory given the relatively small number of bonded samples tested (12 new joints and 9 aged joints).

This experimental work has been performed with only alternate loadings: the mean shear stress is null, or alternatively the R-ratio is equal to -1 . The influence of the mean shear stress $\tau_{m}$ has thus not been investigated. Based on the work of Crocombe and Richardson (41), and Amiable (42), the simplest way to take the influence of this mean stress into account is to add a simple term in the predictor $\sigma_{e q}$ of the proposed fatigue law:

$$
\sigma_{e q}=\left\{\begin{array}{c}
\Delta \tau+c\left|\tau_{m}\right|+b_{o p t} \Delta W \text { if } W_{d}>W_{s} \\
0 \text { if } W_{d} \leq W_{s}
\end{array}\right.
$$

with the coefficient $c$ to identify with additional fatigue tests. An order of magnitude of this parameter can be obtained by remarking that the damage of a stress cycle from 0 to $\tau_{\max }$ in an adhesive joint is the same as the damage of a stress cycle from 0 to $-\tau_{\max }$. This remark implies that an alternate loading 
$\left(-\tau_{\max }, \tau_{\max }\right)$ produces twice the damage of the cycle $\left(0, \tau_{\max }\right)$ or $\left(-\tau_{\max }, 0\right)$, which has been confirmed for bulk rubber specimen in torsion loading (43) (44). One can therefore write it as:

$$
N_{(0, \tau)}=2 N_{(-\tau, \tau)}
$$

If $\Delta W$ is neglected compared to $\Delta \tau$, the following equation is obtained:

$$
\left(\frac{\Delta \tau}{2}+c \frac{\Delta \tau}{2}\right)^{-k}=2(\Delta \tau)^{-k}
$$

which drives to

$$
c \sim 2^{1-1 / k}-1=0.861 \text { for } k=9.65
$$

\section{Conclusion}

In this paper, the lifetime prediction of silicone adhesive joints has been evaluated. The influence of a thermos-oxidative ageing has, in particular, been investigated. This study was done by performing alternate load-controlled shear loadings on new and previously aged adhesive joints.

The experimental results, i.e. fatigue data of both new and aged joints, could be represented by a unique fatigue law with a reasonable spread. As a consequence, we can state that at the first order of magnitude, one can neglect the impact of the thermo-oxidative ageing on the lifetime prediction of the studied silicone adhesive joints. This does not imply that the ageing has no influence on the mechanical properties of the joint, as it was clearly noticed a stiffening of the aged joints compared to the new joints. This point is in accordance with the studies (31) and (29) on elastomeric materials.

It is worth noticing that several important parameters have not been experimentally investigated in this study, such as:

- the loading R-ratio (directly related to the average shear stress $\left|\tau_{m}\right|$ );

- the hydrostatique pressure;

- the temperature during the fatigue tests.

Several assumptions and models are available in the literature that enables to take into account the influence of these parameters. However a complete supplementary fatigue test campaign should be run to experimentally assess or confirm the values of the additional coefficients.

The dissipated energy per cycle by the joint during the test has shown to be an important descriptor of the fatigue lifetime by the introduction of an energy threshold $W_{s}$ in the fatigue law formulation. The introduction of this parameter demands a fine characterization the viscoelastic part of the adhesive joint behavior in order to accurately predict the joint lifetime. It was not the case for silicone adhesive bonding in the absence of fillers (24), where the true strain was the pertinent fatigue indicator. This indicates that the dissipated energy is a better overall indicator for materials with a complex 
microstructure as in the case of the fillers and a high volume fraction where high stress and strain concentrations and various phenomena can be at the origin of fatigue crack initiation.

If the proposed model is a robust approximation for standard engineering applications, detailed observations, extensive testing as well as a homogenization theory of highly filled elastomers are still needed to propose a complete damage evolution model as proposed in (25). 
Appendix A. Determination of the ageing activation energy by Thermo-Gravimetric Analysis (TGA)

Chemical ageing of polymers can be modeled by an Arrhenius law. This law expresses the chemical reaction rate $r$ at a given temperature $T$ in function of an activation energy $E_{a}$ and a prefactor $A$ :

where denotes the Boltzmann constant. Therefore, two chemical ageing characterized by a temperature $T_{i}$ and a time exposure are equivalent from the point of view of the chemical reaction if

, which finally gives the relation of the paragraph 2.2 :

The activation energy $E_{a}$ can be determined by different methods. The method presented in this appendix relies on the measure of the weight-loss reaction rate. The weight-loss reaction rate can be measured with a Thermo-Gravimetric Analysis (TGA) experiment of an adhesive sample. This experiment simply consists in measuring the relative loss of weight of a sample at a given temperature dwell in function of the test time. Different predictors can then be chosen to determine the weight-loss reaction rate, namely:

- the initial slope of the relative weight-loss in function of the time once the temperature dwell is reached;

- the value of the weight-loss at a given time point.

Whatever the chosen predictor, it shall be written as

or equivalently

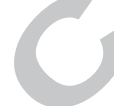

The plot of the logarithm of the predictor

against the inverse of the temperature

lie on a straight line, whose slope is directly linked to the activation energy.

TGA tests were realized at three different temperature dwells: $\quad{ }^{\circ} \mathrm{C}, 225^{\circ} \mathrm{C}$ and $250^{\circ} \mathrm{C}$. The temperature ramp from room temperature to the dwell was to set to n, which makes the ramp last approximately minutes. The tests were performed under a continuous stream of nitrogen.

The Figure 9 (a) displays a TGA test at $250^{\circ} \mathrm{C}$ for 10 hours in terms of temperature and relative weight data. In particular, it can be noticed that the measured weight increases during the initial temperature 
ramp. This non-physically explained phenomenon is a measurement artefact. Then, the relative weight monotonically decreases during the dwell until reaching an asymptotic value. The measurement artefact on the relative weight is present again when cooling the sample at the end of the test. The Figure 9 (b) illustrates the weight-loss for three TGA tests with different temperature dwells. The measurement artefact on the relative weight is noticed for each TGA test during sample heating and cooling. The weight cell presents also a slight drift in time, as illustrated by the small non-physical positive slope of the relative weight at the end of the dwell of the lowest temperatures.

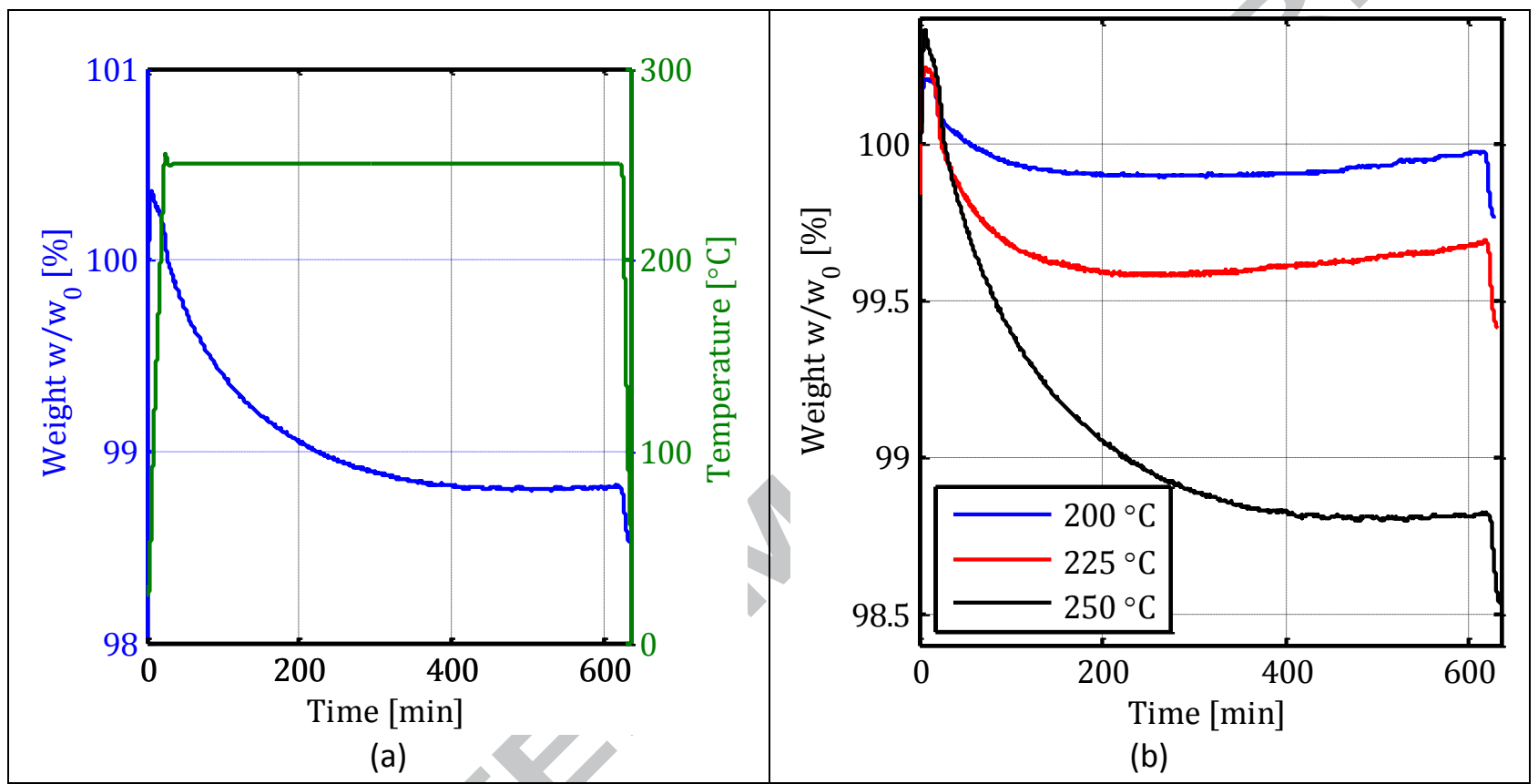

Figure 9: TGA weight-loss and temperature data for a dwell at $250^{\circ} \mathrm{C}$ for 10 hours (a); TGA weight-loss data for $200^{\circ} \mathrm{C}$, $225^{\circ} \mathrm{C}$ and $250^{\circ} \mathrm{C}$ (b)

For these reasons, the initial slope of the relative weight was chosen as the predictor, rather than the relative weight value at a given time point. Indeed, this latter method is clearly more sensitive to weight measurement artefacts and drifts. The slope is effectively measured by simple linear regression of the weight data in the time interval [ $40 \mathrm{mins} ; 60 \mathrm{mins}$ ], because the three curves clearly present a constant slope in this time interval. The measured slopes are displayed in the Table A.2 :

\begin{tabular}{|c|c|}
\hline Temperature dwell & Slope \\
\hline $200^{\circ} \mathrm{C}$ & $2.297 \cdot 10^{-3} \mathrm{~min}^{-1}$ \\
\hline $225^{\circ} \mathrm{C}$ & $4.804 \cdot 10^{-3} \mathrm{~min}^{-1}$ \\
\hline $250^{\circ} \mathrm{C}$ & $9.535 \cdot 10^{-3} \mathrm{~min}^{-1}$ \\
\hline
\end{tabular}

Table A.2: Slopes measured from the TGA tests of Figure 9 (b)

The natural logarithm of the slopes of Table A.2 is plotted against the inverse of the temperature $1 / T$ in Figure 10. A linear regression on this data is realized to finally obtain the activation energy $E_{a}$.

The value obtained for the silicone adhesive is $E_{a}=0.607 \mathrm{eV}=58.6 \mathrm{~kJ} / \mathrm{mol}$ 


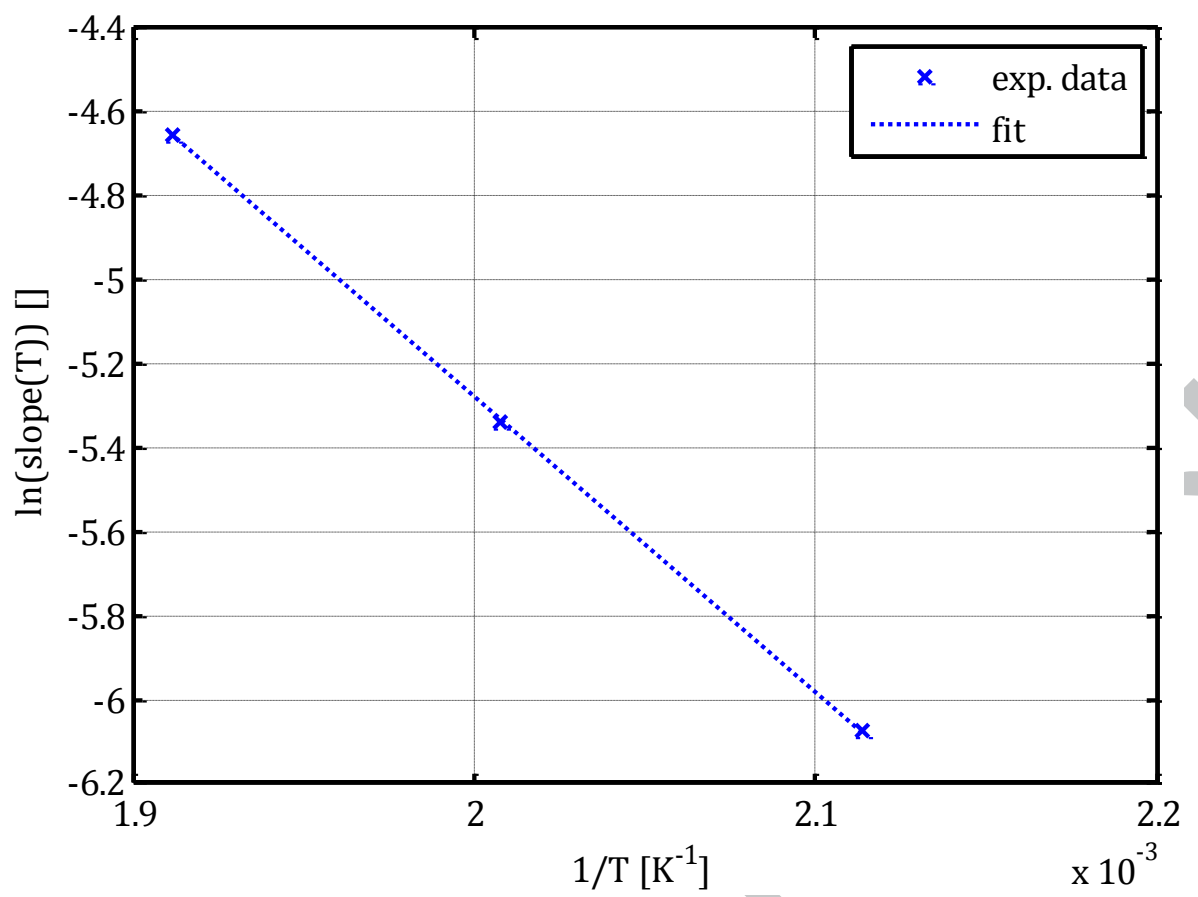

Figure 10: plot of the natural logarithm of the slopes of Table A.2 in function of the inverse of the temperature, and linear regression of this plot.

Appendix B. Table of the fatigue test results

\begin{tabular}{|l|c|c|c|c|c|c|c|}
\hline $\begin{array}{l}\text { Joint } \\
\text { state }\end{array}$ & $\begin{array}{c}\text { Test } \\
\text { result }\end{array}$ & Cycles & $\begin{array}{c}\text { Load } \\
\Delta F[N]\end{array}$ & $\begin{array}{c}\Delta \tau \\
{[\mathrm{MPa}]}\end{array}$ & $\begin{array}{c}\Delta \gamma \\
{[\%]}\end{array}$ & $\begin{array}{c}\Delta W \\
{[\mathrm{MPa}]}\end{array}$ & $\begin{array}{c}W_{d} \\
{[\mathrm{kPa}]}\end{array}$ \\
\hline New & Failure & 97213 & 60 & 2,45 & 25,1 & 0,308 & 24,5 \\
\hline New & Failure & 52678 & 60 & 2,4 & 30,1 & 0,360 & 28,5 \\
\hline New & Failure & 64397 & 60 & 2,25 & 31 & 0,345 & 26,5 \\
\hline New & Failure & 170388 & 50 & 2,01 & 20,6 & 0,208 & 16,25 \\
\hline New & Failure & 293834 & 50 & 2,04 & 18,6 & 0,190 & 16 \\
\hline New & Failure & 225639 & 50 & 2,04 & 23 & 0,233 & 23 \\
\hline New & Failure & 1562443 & 40 & 1,64 & 19,4 & 0,158 & 17,5 \\
\hline New & Failure & 1948156 & 40 & 1,64 & 17,8 & 0,145 & 14,5 \\
\hline New & Failure & 332227 & 40 & 1,64 & 20 & 0,165 & 16,5 \\
\hline New & Failure & 732370 & 40 & 1,62 & 17,8 & 0,143 & 18 \\
\hline New & Failure & 317236 & 50 & 2,05 & 20 & 0,203 & 13,75 \\
\hline New & Failure & 4368011 & 40 & 1,65 & 11,4 & 0,093 & 9,5 \\
\hline New & Failure & 24846 & 50 & 2,04 & 16,3 & 0,168 & 16 \\
\hline Aged & Failure & 3342 & 65 & 2,73 & 9,5 & 0,130 & 12 \\
\hline Aged & Survivor & $1 \mathrm{E}+07$ & 50 & 2,08 & 5,65 & 0,058 & 2,1 \\
\hline Aged & Failure & 505230 & 50 & 2 & 19 & 0,190 & 14 \\
\hline Aged & Survivor & $1,00 \mathrm{E}+07$ & 60 & 2,5 & 7,65 & 0,096 & 4,25 \\
\hline
\end{tabular}




\begin{tabular}{|c|c|c|c|c|c|c|c|}
\hline Aged & Failure & 9737 & 70 & 2,85 & 9,7 & 0,140 & 12,75 \\
\hline Aged & Failure & 95724 & 60 & 2,47 & 9,4 & 0,116 & 7,1 \\
\hline Aged & Failure & 3950 & 65 & 2,56 & 11 & 0,140 & 12,75 \\
\hline Aged & Survivor & $1 \mathrm{E}+07$ & 55 & 2,34 & 3,35 & 0,039 & 1,95 \\
\hline Aged & Failure & 12456 & 60 & 2,46 & 11 & 0,135 & 13,25 \\
\hline
\end{tabular}

Appendix C. Damage accumulation in the joint during the fatigue test

The load and the displacement signals enable to get access to the joint viscoelastic behavior in terms of magnitude of complex shear modulus $\left|G^{*}\right|=\Delta \tau / \Delta \gamma$ and loss factor $\tan \delta$, where $\delta$ is defined in section 3 in the definition of the energy dissipated per cycle $W_{d}$. The evolution of $\left|G^{*}\right|$ and $\delta$ is displayed Figure 11 (a) and (b) for a joint that failed (a) and a joint that survived (b) the fatigue test after $10^{7}$ loading cycles. Given the small values experimentally measured for the phase shift $\delta$, the appromixation $\tan \delta \sim \delta$ is considered valid.

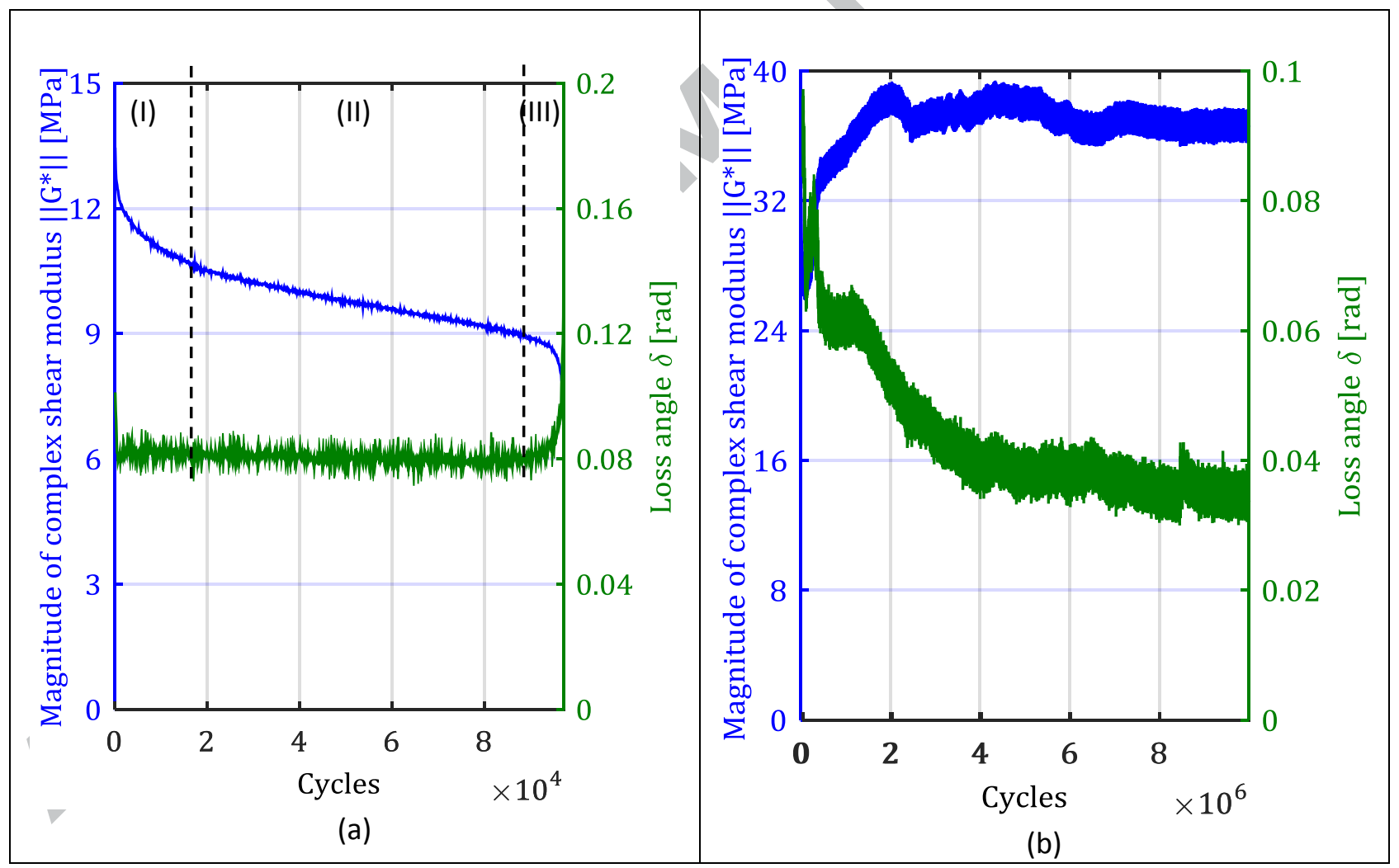

Figure 11 : evolution of the stiffness $\left|G^{*}\right|$ and the loss angle $\delta$ during a fatigue test for a failed joint (a) and a survivor (b). The failed joint illustrated in (a) was a new joint, however similar evolution were noticed for failed aged joints. Survivors (b) only happened for aged joints.

In the case of a failure, three different stages noticed Figure 11 (a) can be distinguished as explained in (39): 
- The first stage (I) presents a quick decrease of the stiffness, the loss factor remains constant.

- The second stage (II) is characterized by a stable linear decrease of the stiffness $\left|G^{*}\right|$, the loss factor still being kept constant.

- The third and last stage (III) shows a dramatic decrease of the stiffness $\left|G^{*}\right|$ down to failure, coupled with a sudden increase of the loss factor. This last stage probably corresponds to the crack propagation phase, where the dissipative phenomena at the crack tip contribute to the increase of the loss factor. It can be noticed here that even for a "reasonable" test duration of about $10^{5}$ cycles, the last stage is a lot shorter than the two first stages. This means that most of the fatigue test is spent to initiate the crack.

Such an evolution of the joint stiffness, and especially the distinction between stage 2 and 3 , can be related to the evolution of the natural frequencies of a bonded assembly illustrated in (45): the drop of the resonant frequency noticed by the authors of (45) can indeed be explained by the decrease of the joint stiffness.

In the case of a survivor (see Figure 11 (b)), after a rather long adaptation phase, the stiffness does not significantly evolve and the loss factor is also stabilized. It is worth noticing that its asymptotic value is twice smaller than the stabilized value of the failure plotted in Figure 11 (a). The three-stage separation previously identified for the failed joint is not clear any more in the case of a survivor. 


\section{References}

1. Adams, R. D., Comyn, J. et Wake, W. C. Structural adhesive joints in engineering. s.I. : Springer Science \& Business Media, 1997.

2. Performance of butt strap joints for marine applications. Jarry, E. et Shenoi, R. A. 3, 2006, International journal of adhesion and adhesives, Vol. 26, pp. 162-176. http://dx.doi.org/10.1016/j.ijadhadh.2005.01.010.

3. Cowling, M. J. A review of adhesive bonding for offshore structures. s.l. : Health and Safety Executive, 1997.

4. Reliability and failure mechanism of isotropically conductive adhesive joints. Li, L. et Morris, J. E. 1995. Electronic components and technology conference. pp. 114-120. http://dx.doi.org/ 10.1109/ECTC.1995.514370.

5. A literature survey on fatigue analysis approaches for rubber. Mars, W. V. et Fatemi, A. 9, s.I. : Elsevier, 2002, International Journal of Fatigue, Vol. 24, pp. 949-961.

6. Fatigue in adhesively bonded joints: a review. Abdel Wahab, M. M. 2012, ISRN Materials Science, Vol. 2012.

7. Strength wearout of adhesively bonded joints under constant amplitude fatigue. Shenoy, V., et al. 5, 2009, International Journal of Fatigue, Vol. 31, pp. 820-830.

8. Load ratio effect on the fatigue behaviour of adhesively bonded joints: an enhanced damage model. Katnam, K. B., et al. 3, 2010, The Journal of Adhesion, Vol. 86, pp. 257-272.

9. Evaluation of fatigue characteristics for adhesively-bonded composite stepped lap joint. Kim, J. H., Park, B. J. et Han, Y. W. 1, 2004, Composite Structures, Vol. 66, pp. 69-75.

10. Prediction of fatigue thresholds in adhesively bonded joints using damage mechanics and fracture mechanics. Abdel Wahab, M. M., et al. 7, 2001, Journal of adhesion science and technology, Vol. 15, pp. 763-781.

11. Evaluation of fatigue damage in adhesive bonding: part 2: single lap joint. Abdel Wahab, M. M., et al. 2, 2010, Journal of Adhesion Science and Technology, Vol. 24, pp. 325-345.

12. Fatigue behaviour and damage evolution of single lap bonded joints in composite material.

Quaresimin, M. et Ricotta, M. 2, 2006, Composites Science and Technology, Vol. 66, pp. 176-187.

13. Fatigue damage evaluation of adhesively bonded butt joints with a rubber-modified epoxy adhesive. Imanaka, M., et al. 1, 2003, Journal of adhesion science and technology, Vol. 17, pp. 981-994. 
14. Composite bonded joints under mode I fatigue loading. Fernandez, M. V., et al. 5, 2011, International journal of adhesion and adhesives, Vol. 31, pp. 280-285.

15. Fatigue crack propagation in adhesively bonded joints. Abdel Wahab, M. M., et al. 2003, Key Engineering Materials, Vol. 251, pp. 229-234.

16. Simulation of mixed-mode I/II fatigue crack propagation in adhesive joints with a modified cohesive zone model. Pirondi, A. et Moroni, F. 18, 2011, Journal of Adhesion Science and Technology, Vol. 25, pp. 2483-2499.

17. Predicting fatigue damage in adhesively bonded joints using a cohesive zone model. Khoramishad, $\mathbf{H} .$, et al. 7, 2010, International Journal of fatigue, Vol. 32, pp. 1146-1158.

18. Effect of substrate material on fatigue crack propagation rate of adhesively bonded DCB joints. Ishii, K. 20, 2011, Journal of Adhesion Science and Technology, Vol. 25, pp. 2775-2787.

19. A new testing methodology for the assessment of fatigue properties of structural adhesives. Blanchard, C., Chateauminois, A. et Vincent, L. 4, 1996, International journal of adhesion and adhesives, Vol. 16, pp. 289-299.

20. An experimental and numerical study of the static and fatigue performance of a composite adhesive repair. Tenchev, R. T. et Falzon, B. G. 2008, Key Engineering Materials, Vol. 383, pp. 25-34.

21. Effect of adhesive thickness on fatigue and fracture of toughened epoxy joints--Part I: Experiments. Azari, S., Papini, M. et Spelt, J. K. 1, 2011, Engineering Fracture Mechanics, Vol. 78, pp. 153-162.

22. Experimental analysis of the behavior of adhesively bonded joints under tensile/compression--shear cyclic loadings. Thevenet, D., et al. 2013, International Journal of Adhesion and Adhesives, Vol. 44, pp. 15-25.

23. Evaluation of fatigue life of adhesively bonded aluminum single-lap joints using interfacial parameters. Jen, Y.-M. et Ko, C.-W. 2, 2010, International Journal of Fatigue, Vol. 32, pp. 330-340.

24. Failure behaviour of silicone adhesive in bonded connections with simple geometry. Staudt, Y., Odenbreit, C. et Schneider, J. 2018, International Journal of Adhesion and Adhesives, Vol. 82, pp. 126138.

25. A micro-mechanically based continuum damage model for fatigue life prediction of filled rubbers. Grandcoin, J., Boukamel, A. et Lejeunes, S. 6, 2014, International Journal of Solids and Structures, Vol. 51, pp. $1274-1286$.

26. Fatigue resistance of an aluminium one-component polyurethane adhesive joint for the automotive industry: Effect of surface roughness and adhesive thickness. Boutar, Y., et al. 2018, International Journal of Adhesion and Adhesives. 
27. Environmental aging and deadhesion of siloxane-polyimide-epoxy adhesive. Murray, S., Hillman, C. et Pecht, M. 3, 2003, IEEE Transactions on Components and Packaging Technologies, Vol. 26, pp. 524-531.

28. The effects of ageing and environment on the fatigue life of adhesive joints. Su, N., Mackie, R. I. et Harvey, W. J. 2, 1992, International journal of adhesion and adhesives, Vol. 12, pp. 85-93.

29. Fatigue behaviour of an elastomer under consideration of ageing effects. Neuhaus, C., et al. 2017, International Journal of Fatigue, Vol. 104, pp. 72-80.

30. A critical comparison of shear tests for adhesive joints. Jouan, A. et Constantinescu, A. 2018, International Journal of Adhesion and Adhesives, Vol. 10.1016/j.ijadhadh.2018.02.035.

31. Thermo-oxidative ageing of elastomers: A modelling approach based on a finite strain theory. Johlitz, M., Dierks, N. et Lion, A. 2014, International Journal of Plasticity, Vol. 63, pp. 138-151.

32. Leguillon, D. et Sanchez-Palencia, E. Computation of singular slutions in elleptic problems and elasticity. s.I. : John Wiley \& Sons, 1987.

33. The Exponential Law of Endurance Tests. Basquin, O. H. 1910. Vol. 10, pp. 625-630.

34. A state-of-the-art review on fatigue life prediction methods for metal structures. Cui, W. 1, 2002, Journal of marine science and technology, Vol. 7, pp. 43-56.

35. An energetic approach in thermomechanical fatigue for silicon molybdenum cast iron. Charkaluk, E. et Constantinescu, A. 3, 2000, Materials at high temperatures, Vol. 17, pp. 373-380.

36. A computational approach to thermomechanical fatigue. Constantinescu, A., et al. 8, 2004, International Journal of fatigue, Vol. 26, pp. 805-818.

37. The force on an elastic singularity. Eshelby, J. D. 877, 1951, Philosophical Transactions of the Royal Society of London A: Mathematical, Physical and Engineering Sciences, Vol. 244, pp. 87-112.

38. Definition of a new predictor for multiaxial fatigue crack nucleation in rubber. Verron, E. et Andriyana, A. 2, 2008, Journal of the Mechanics and Physics of Solids, Vol. 56, pp. 417-443.

39. Cyclic hardening, softening, and crack growth during high temperature fatigue. Skelton, R. P. 11, 1993, Materials science and technology, Vol. 9, pp. 1001-1008.

40. Jouan, Alexandre. Influence of ageing in confined atmosphere on the lifetime prediction of adhesive joints. Ecole Polytechnique. 2018. PhD dissertation.

41. Assessing stress state and mean load effects on the fatigue response of adhesively bonded joints.

Crocombe, A. D. et Richardson, G. 1, 1999, International Journal of Adhesion and Adhesives, Vol. 19, pp. 19-27. 
42. A comparison of lifetime prediction methods for a thermal fatigue experiment. Amiable, S., et al. 7, 2006, International Journal of Fatigue, Vol. 28, pp. 692-706.

43. Saintier, N. Multiaxial fatigue of a filled NR elastomer: damage mechanisms and local initiation criterion. Ecole Nationale Supérieure des Mines de Paris. 2001. PhD dissertation.

44. Raoult, I. Elastomer structures under cyclic loading: behavior, fatigue, lifetime. Ecole Polytechnique. 2005. PhD dissertation.

45. Influence of nanoalumina particles on the static and high-cycle fatigue properties of peel-loaded adhesive-bonded joints. Kubit, A., Zielecki, W. et Drabczyk, M. 4, 2016, Strength of Materials, Vol. 48, pp. $515-523$. 


\section{Highlights}

1. stress-life approach applied to a silicone-based conductive adhesive

2. experimental fatigue test setup for adhesive joints

3. fatigue of thermo-oxydatively aged silicone adhesive joints

4. fatigue law unifying data of both new and thermo-oxydatively aged joints 